\title{
Perfusion and Diffusion Variables Predict Early Neurological Deterioration in Minor Stroke and Large Vessel Occlusion
}

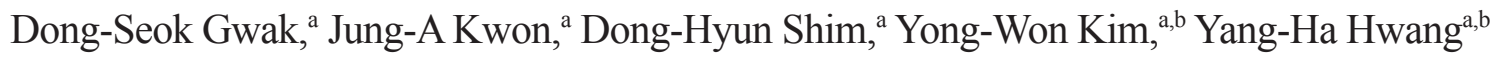 \\ aDepartment of Neurology, Kyungpook National University Hospital, Daegu, Korea \\ bDepartment of Neurology, School of Medicine, Kyungpook National University, Daegu, Korea
}

\begin{abstract}
Background and Purpose Patients with acute large vessel occlusion (LVO) presenting with mild stroke symptoms are at risk of early neurological deterioration (END). This study aimed to identify the optimal imaging variables for predicting END in this population.

Methods We retrospectively analyzed 94 patients from the prospectively maintained institutional stroke registry admitted between January 2011 and May 2019, presenting within 24 hours after onset, with a baseline National Institutes of Health Stroke Scale score $\leq 5$ and anterior circulation LVO. Patients who underwent endovascular therapy before END were excluded. Volumes of Tmax delay (at $>2,>4,>6$, $>8$, and $>10$ seconds), mismatch (Tmax $>4$ seconds - diffusion-weighted imaging [DWI] and Tmax $>6$ seconds - DWI), and mild hypoperfusion lesions (Tmax 2-6 and 4-6 seconds) were measured. The association of each variable with END was examined using receiver operating characteristic curves. The variables with best predictive performance were dichotomized at the cutoff point maximizing Youden's index and subsequently analyzed using multivariable logistic regression.

Results END occurred in 39.4\% of the participants. The optimal variables were identified as Tmax $>6$ seconds, Tmax $>6$ seconds - DWI, and Tmax 4-6 seconds with cut-off points of 53.73, 32.77, and $55.20 \mathrm{~mL}$, respectively. These variables were independently associated with END (adjusted odds ratio [aOR], 12.78 [95\% confidence interval $(\mathrm{Cl}), 3.36$ to 48.65 ]; aOR, 5.73 [95\% Cl, 2.04 to 16.08]; and $\mathrm{aOR}, 9.13$ [95\% $\mathrm{Cl}, 2.76$ to 30.17$]$, respectively).

Conclusions Tmax $>6$ seconds, Tmax $>6$ seconds - DWI, and Tmax 4-6 seconds could identify patients at high risk of END following minor stroke due to LVO.
\end{abstract}

Keywords Clinical deterioration; Magnetic resonance imaging; Stroke

\section{Introduction}

Patients presenting with mild symptoms of acute ischemic stroke are common and account for approximately half of all patients. ${ }^{1,2}$ Despite the perception that minor stroke is a benign condition, nearly one-third of patients have persistent disability. ${ }^{3-5}$ In particular, up to $30 \%$ of minor strokes are caused by
Correspondence: Yang-Ha Hwang Department of Neurology, Kyungpook National University Hospital, School of Medicine, Kyungpook National University, 130 Dongdeok-ro, Jung-gu, Daegu 41944, Korea

Tel: +82-53-420-5765

Fax: +82-53-422-4265

E-mail:yangha.hwang@gmail.com https://orcid.org/0000-0002-66657481

Received: April 28, 2020

Revised: August 31, 2020

Accepted: September 1, 2020 
spective studies have reported contradictory results on the effects of EVT in minor stroke. ${ }^{6,16-22}$ Therefore, it is crucial to identify patients who are most likely to benefit from EVT in minor stroke with LVO.

Over half of minor stroke patients with LVO who were medically treated showed excellent outcomes at 3 months ${ }^{6,18-22}$ and appear to be inappropriate for EVT. Meanwhile, patients who experience neurological worsening during best medical treatment show less favorable outcomes than those undergoing immediate EVT, even if they receive rescue EVT following clinical deterioration., ${ }^{60,21}$ Thus, identifying patients who are likely to have early neurological deterioration (END) is clinically important, as immediate EVT may be considered as one of the treatment options in this patient group.

Infarct growth in the same vascular territory is the most common mechanism of END. ${ }^{23}$ Theoretically, the transition from oligemic tissue to a functionally impaired state may lead to clinical deterioration. Based on this theory, those with a larger area of non-infarcted but hypoperfused tissue may be at greater risk of developing END. Imaging variables from perfusionweighted imaging (PWI) and diffusion-weighted imaging (DWI) could be potential surrogate markers for hypoperfused brain regions. Using these variables, several studies have demonstrated that mismatch between PWI and DWI is associated with infarct growth ${ }^{24}$ and poor outcomes, including END. ${ }^{25,26}$ However, due to the heterogeneity of study participants in previous studies, whether these imaging variables predict END in patients with LVO presenting with mild symptoms remains unknown. We aimed to investigate the optimal imaging variables using PWI and DWI for the prediction of END in this population.

\section{Methods}

\section{Study population}

We retrospectively reviewed consecutive patients with ischemic stroke from our prospectively maintained institutional stroke registry. We identified patients who met the following inclusion criteria: (1) admission to Kyungpook National University Hospital between January 2011 and May $2019(n=7,945)$; (2) arrival within 24 hours of the last known normal $(n=5,465)$; (3) baseline NIHSS score of five or less $(n=3,001)$; (4) pre-stroke modified Rankin Scale (mRS) of 0 or $1(n=2,705)$; and (5) acute LVO in the anterior circulation (defined by occlusion of the intracranial internal carotid artery, proximal segment of the middle cerebral artery [M1 or M2 trunk], or tandem occlusion) documented on the initial computed tomography angiography or magnetic resonance angiography $(n=158)$. Patients with LVO due to moyamoya disease were excluded $(n=15)$. Patients were also excluded if they were treated with EVT before END $(n=14)$ or did not undergo PWI $(n=35)$. Finally, 94 patients were eligible for analysis (Supplementary Figure 1). The study protocol was approved by the Institutional Review Board (IRB approval number: KNUH 2020-04-001). The need for informed consent was waived due to the retrospective nature of the study and the minimal risk to study participants. All study participants were fully anonymized.

\section{Data collection}

Baseline demographics and clinical characteristics were obtained from the institutional stroke registry database or through a review of electronic medical records. The following variables were collected: age, sex, baseline NIHSS score, onset-to-door time, pre-stroke $m R S$, stroke mechanism classified according to the Trial of ORG 10172 in Acute Stroke Treatment (TOAST) criteria with some modifications, ${ }_{1}^{27}$ occluded vessel location, hypertension, diabetes mellitus, hyperlipidemia, atrial fibrillation, myocardial infarction or angina, history of smoking, baseline blood pressure, type of recanalization therapy, and laboratory data including baseline leukocyte count, hemoglobin, hematocrit, platelet count, erythrocyte sedimentation rate, C-reactive protein, fibrinogen, and glucose level.

Ischemic core lesions identified on DWI were measured using an automated software program with minimal manual editing (Olea Sphere 3.0, SP6, Olea Medical, La Ciotat, France). Dynamic susceptibility PWI was performed, and the Tmax value of the residue function generated by deconvolution was obtained. The Tmax delay volumes (Tmax $>2,4,6,8$, and 10 seconds) were measured using the same program. The Tmax delay lesion of the optimal threshold was determined as a critical hypoperfusion lesion reflecting its association with neurological worsening. Mismatch volumes (Tmax $>4$ seconds - DWI volume and Tmax $>6$ seconds - DWI volume) and mild hypoperfusion lesions where perfusion deficits were milder than the penumbra ${ }^{28,29}$ (Tmax 2-6 seconds and Tmax 4-6 seconds) were also recorded.

The outcome variables, including END and unfavorable functional outcome (defined as an mRS of 2 to 6 ) at 3 months were collected. To capture neurological worsening sensitively and exclude systemic causes, we defined END as any new neurological symptom or any neurological worsening with an increase in the total NIHSS score of 2 or more, or an increase in the motor score $(5 a-6 b)$ of one or more within 72 hours of stroke onset. ${ }^{30-32}$ It was immediately documented by the onduty neurologist or attending physician.

\section{Statistical analysis}

Data are summarized as number (\%), mean \pm standard devia- 
tion, or median (interquartile range [IQR]). Comparisons of variables between the groups with or without END were made using Student's t-test or the Mann-Whitney U test for continuous variables, and Pearson's chi-square test or Fisher's exact method for categorical variables, as appropriate. In addition, the association of END with unfavorable outcomes was tested using Pearson's chi-square test.

The optimal threshold for the Tmax delay lesion was defined as that showing the best predictive performance for END and was determined using receiver operating characteristic (ROC) curve analysis. For the variables of mismatch volume and mild hypoperfusion lesions of each Tmax threshold, the optimal threshold was also obtained in the same way. Furthermore, these continuous variables were dichotomized at the cutoff point maximizing Youden's index (sensitivity+specificity-1). ${ }^{33}$ The best thresholds of Tmax delay lesion (critical hypoperfusion lesion), mismatch volume, and mild hypoperfusion lesion were subsequently analyzed to derive predictive models using multivariable logistic regression analysis.

Univariable logistic regression analyses were performed to examine the associations of critical hypoperfusion lesions, mismatch volumes, and mild hypoperfusion lesions with clinical outcomes. All variables that were different between the two groups (defined as $P<0.1$ ) were then included in the backward stepwise multivariable logistic regression analyses to adjust for the effects of confounding variables. To avoid multicollinearity among the imaging variables, critical hypoperfusion lesions, mismatch volumes, and mild hypoperfusion lesions were tested in separate models. A two-sided $P$-value $<0.05$ was considered statistically significant. All statistical analyses were performed using SPSS version 25.0 (IBM Co., Armonk, NY, USA).

\section{Results}

A total of 94 patients with acute LVO presenting with mild symptoms were included in this study. Among them, 37 (39.4\%) patients experienced END. In all cases, the mechanism of END was progressive stroke in the same vascular territory. Baseline demographics and clinical characteristics are shown in Table 1. We found no statistical difference in the baseline characteristics between the groups with or without END, except for onset-to-door time and type of recanalization therapy. The onset-to-door time (hours) was shorter in patients with END (2.50 [IQR, 1.45 to 9.33]) than in those without END (4.28 [IOR, 1.58 to 13.67$] ; P=0.019$ ). Patients who experienced END were more frequently treated with intravenous tissue-type plasminogen activator (tPA; $54.1 \%$ ) than patients without END $(14.0 \% ; P<0.001)$. The PWI and DWI variables are presented in
Table 2. Initial hypoperfusion lesion volumes with a Tmax threshold of $>4,>6,>8$, and $>10$ seconds were larger in the END group than in the non-END group. Mismatch volumes with a Tmax threshold $>4$ and $>6$ seconds and mild hypoperfusion lesion of Tmax 4-6 seconds were also larger in the END group. Patients with END were more likely to have an unfavorable outcome at 3 months than those without END (35.1\% vs. $7.0 \%, P=0.001)$. Of the patients with END, $62.2 \%(23 / 37)$ received EVT following neurological worsening (Table 1). However, $30.4 \%(7 / 23)$ of these patients showed unfavorable outcomes at 3 months despite rescue EVT.

The ROC analysis of imaging variables for each threshold and their association with END identified Tmax $>6$ seconds, Tmax $>6$ seconds - DWI, and Tmax 4-6 seconds as the optimal values for further analysis (area under the curve $=0.725[95 \%$ confidence interval (CI), 0.622 to $0.829 ; P<0.001] ; 0.753$ [95\% $\mathrm{Cl}, 0.654$ to $0.852 ; P<0.001]$; and 0.648 [95\% $\mathrm{Cl}, 0.535$ to $0.762 ; P=0.016]$, respectively). Based on Youden's Index, the optimal volume of Tmax $>6$ seconds for predicting END was $\geq 53.73 \mathrm{~mL}$, Tmax $>6$ seconds - DWI was $\geq 32.77 \mathrm{~mL}$, and Tmax 4-6 seconds was $\geq 55.20 \mathrm{~mL}$ (Table 3 ).

In the univariate logistic regression analysis, patients who had a Tmax $>6$ seconds of $\geq 53.73 \mathrm{~mL}$ (the group with a large critical hypoperfusion lesion volume) were more likely to experience END than those with a Tmax $>6$ seconds of $<53.73 \mathrm{~mL}$ (odds ratio [OR], 6.77; 95\% Cl, 2.44 to 18.77; $P<0.001$ ) (Table 4). In addition, patients who had a mismatch volume $\geq 32.77$ $\mathrm{mL}$ (the mismatch pattern group) and mild hypoperfusion lesion of Tmax 4-6 seconds $\geq 55.20 \mathrm{~mL}$ (the group with a large mild hypoperfusion lesion volume) were more likely to experience END $(\mathrm{OR}, 5.34$ [95\% $\mathrm{Cl}, 2.17$ to $13.11 ; P<0.001]$ and 4.21 [95\% Cl, 1.75 to $10.15 ; P=0.001]$, respectively). Due to the multicollinearity of these variables, each imaging variable was tested in a separate multivariable logistic regression model. In model 1, adjusting for the difference in variables between the two groups, patients with large critical hypoperfusion lesion volumes were still significantly more likely to experience END (adjusted OR [aOR], 12.78; 95\% Cl, 3.36 to 48.65; $P<0.001$ ). Furthermore, the association between the mismatch pattern and END remained significant in model 2 (aOR, 5.73; 95\% Cl, 2.04 to 16.08 ; $P=0.001$ ). In model 3, patients with large mild hypohypoperfusion lesion volumes were independently associated with END ( $\mathrm{aOR}, 9.13 ; 95 \% \mathrm{Cl}, 2.76$ to $30.17 ; P<0.001)$. Those who received tPA also showed an independent association with END in all models.

Large critical hypoperfusion lesion volume, mismatch pattern, and large mild hypoperfusion lesion volume were associated with increased odds of an unfavorable outcome at 3 
Table 1. Baseline characteristics of the patients

\begin{tabular}{|c|c|c|c|c|}
\hline Characteristic & All $(n=94)$ & END $(n=37)$ & Non-END $(n=57)$ & $P$ \\
\hline Age (yr) & $66.9 \pm 13.0$ & $67.2 \pm 11.8$ & $66.8 \pm 13.9$ & 0.875 \\
\hline Men & 49 (52.1) & $16(43.2)$ & $33(57.9)$ & 0.165 \\
\hline Baseline NIHSS & $2.12 \pm 1.63$ & $2.08 \pm 1.64$ & $2.14 \pm 1.64$ & 0.865 \\
\hline Onset-to-door time (hr) & $3.23(1.45-9.33)$ & $2.50(1.09-5.10)$ & $4.28(1.58-13.67)$ & 0.019 \\
\hline Pre-stroke mRS & & & & 0.377 \\
\hline 0 & $80(85.1)$ & 30 (81.1) & $50(87.7)$ & \\
\hline 1 & $14(14.9)$ & $7(18.9)$ & $7(12.3)$ & \\
\hline Stroke mechanism & & & & 0.448 \\
\hline LAA & $42(44.7)$ & $15(40.5)$ & $27(47.4)$ & \\
\hline CE & $36(38.3)$ & $17(47.2)$ & 19 (33.3) & \\
\hline Other determined & $0(0)$ & $0(0)$ & $0(0)$ & \\
\hline Undetermined & $16(17.0)$ & $5(13.5)$ & $11(19.3)$ & \\
\hline Site of occlusion & & & & 0.553 \\
\hline Intracranial ICA & $7(7.4)$ & $4(10.8)$ & $3(5.3)$ & \\
\hline Tandem & $6(6.4)$ & $3(8.1)$ & $3(5.3)$ & \\
\hline MCA M1 & 44 (46.8) & $18(48.6)$ & $26(45.6)$ & \\
\hline MCA M2 trunk & $37(39.4)$ & $12(32.4)$ & 25 (43.9) & \\
\hline Hypertension & $63(67.0)$ & $28(75.7)$ & $35(61.4)$ & 0.150 \\
\hline Diabetes mellitus & $25(26.6)$ & $12(32.4)$ & $13(22.8)$ & 0.302 \\
\hline Hyperlipidemia & $37(39.4)$ & $17(45.9)$ & $20(35.1)$ & 0.292 \\
\hline Atrial fibrillation & $26(27.7)$ & $11(29.7)$ & $15(26.3)$ & 0.718 \\
\hline Ml or angina & $9(9.6)$ & $3(8.1)$ & $6(10.5)$ & 1.000 \\
\hline Prior stroke & $11(11.7)$ & $4(10.8)$ & $7(12.3)$ & 1.000 \\
\hline Smoking & $19(20.2)$ & $6(16.2)$ & $13(22.8)$ & 0.437 \\
\hline $\mathrm{SBP}(\mathrm{mm} \mathrm{Hg})$ & $157.2 \pm 31.1$ & $151.4 \pm 30.8$ & $161.0 \pm 31.0$ & 0.143 \\
\hline $\mathrm{DBP}(\mathrm{mm} \mathrm{Hg})$ & $86.6 \pm 17.0$ & $86.7 \pm 15.2$ & $86.5 \pm 18.2$ & 0.961 \\
\hline Leukocyte count $(n / \mu \mathrm{L})$ & $8,075.1 \pm 2,324.8$ & $8,358.6 \pm 2,268.8$ & $7,891.1 \pm 2,361.9$ & 0.343 \\
\hline Hemoglobin (g/dL) & $13.7 \pm 1.5$ & $13.7 \pm 1.4$ & $13.7 \pm 1.6$ & 0.983 \\
\hline Hematocrit (\%) & $39.9 \pm 4.1$ & $39.8 \pm 3.6$ & $40.0 \pm 4.5$ & 0.835 \\
\hline Platelet count $(n / \mu \mathrm{L})$ & $245,053 \pm 74,857$ & $257,730 \pm 72,276$ & $236,825 \pm 75,978$ & 0.187 \\
\hline $\mathrm{ESR}(\mathrm{mm} / \mathrm{hr})$ & $10.0(5.0-19.0)$ & $9.0(5.0-19.0)$ & $11.0(5.5-19.0)$ & 0.645 \\
\hline $\mathrm{CRP}(\mathrm{mg} / \mathrm{dL})$ & $0.25(0.08-0.34)$ & $0.29(0.06-0.29)$ & $0.24(0.09-0.42)$ & 0.660 \\
\hline Fibrinogen (mg/dL) & $287.2 \pm 82.7$ & $301.2 \pm 98.2$ & $278.1 \pm 70.4$ & 0.221 \\
\hline Baseline glucose (mg/ dL) & $143.8 \pm 51.4$ & $152.2 \pm 49.8$ & $138.2 \pm 52.1$ & 0.201 \\
\hline \multicolumn{5}{|c|}{ Type of recanalization therapy } \\
\hline IV tPA & $28(29.8)$ & $20(54.1)$ & $8(14.0)$ & $<0.001$ \\
\hline Rescue EVT & $23(24.5)$ & $23(62.2)$ & $0(0)$ & $<0.001$ \\
\hline
\end{tabular}

Values are presented as mean \pm standard deviation, number (\%), or median (interquartile range).

END, early neurological deterioration; NIHSS, National Institutes of Health Stroke Scale; mRS, modified Rankin Scale; LAA, large artery atherosclerosis; CE, cardioembolism; ICA, internal carotid artery; MCA, middle cerebral artery; MI, myocardial infarction; SBP, systolic blood pressure; DBP, diastolic blood pressure; ESR, erythrocyte sedimentation rate; CRP, C-reactive protein; IV tPA, intravenous tissue-type plasminogen activator; EVT, endovascular therapy.

months (OR, 11.82 [95\% Cl, 3.55 to 39.29; $P<0.001] ; \mathrm{OR}, 5.69$ [95\% $\mathrm{Cl}, 1.69$ to $19.13 ; P=0.005]$; and $\mathrm{OR}, 4.44[95 \% \mathrm{Cl}, 1.42$ to $13.95 ; P=0.011]$, respectively) (Table 5). We also found that these variables were independently associated with an unfa- vorable outcome at 3 months, even after adjusting for confounding variables $(\mathrm{aOR}, 23.72[95 \% \mathrm{Cl}, 4.79$ to 117.47 ; $P<0.001$ ]; aOR, 12.47 [95\% $\mathrm{Cl}, 2.43$ to 64.09; $P=0.003$ ]; and aOR, 5.61 [95\% Cl, 1.56 to $20.19 ; P=0.008$ ], respectively). Oth- 
Table 2. Perfusion- and diffusion-weighted imaging variables

\begin{tabular}{|c|c|c|c|c|}
\hline Variable & All $(n=94)$ & Patients with END $(n=37)$ & Patients without END $(n=57)$ & $P$ \\
\hline Initial DWI volume (mL) & $1.34(0.00-5.61)$ & $0.56(0.00-3.87)$ & $1.87(0.45-5.88)$ & 0.054 \\
\hline $\operatorname{Tmax}>2 \sec (\mathrm{mL})$ & 217.62 (156.56-274.25) & 243.66 (153.83-297.30) & 202.64 (157.97-272.31) & 0.091 \\
\hline $\operatorname{Tmax}>4 \sec (\mathrm{mL})$ & $84.24(47.78-120.57)$ & $108.33(64.04-165.55)$ & $65.60(41.43-95.93)$ & $<0.001$ \\
\hline $\operatorname{Tmax}>6 \sec (\mathrm{mL})$ & $28.97(10.15-56.67)$ & $40.93(22.43-67.57)$ & $21.38(3.31-42.65)$ & $<0.001$ \\
\hline Tmax $>8 \mathrm{sec}(\mathrm{mL})$ & $12.53(0.00-25.10)$ & $21.34(4.16-41.56)$ & $7.63(0.00-18.73)$ & 0.001 \\
\hline Tmax $>10 \mathrm{sec}(\mathrm{mL})$ & $3.85(0.00-12.70)$ & $11.08(0.00-17.50)$ & $0.00(0.00-8.74)$ & 0.005 \\
\hline Tmax >4 sec - DWI (mL) & $75.21(43.27-118.17)$ & $105.70(64.00-162.93)$ & $63.17(34.99-90.24)$ & $<0.001$ \\
\hline Tmax $>6 \mathrm{sec}-\mathrm{DWI}(\mathrm{mL})$ & $24.96(6.45-46.25)$ & $40.93(19.53-63.21)$ & $16.25(1.00-34.93)$ & $<0.001$ \\
\hline $\operatorname{Tmax} 2-6 \mathrm{sec}(\mathrm{mL})$ & 185.54 (131.62-229.11) & 198.02 (122.93-227.93) & $184.90(134.13-229.69)$ & 0.998 \\
\hline Tmax 4-6 sec (mL) & 47.19 (28.10-76.63) & $62.08(33.46-81.68)$ & $42.03(24.06-67.48)$ & 0.004 \\
\hline
\end{tabular}

Values are presented as median (interquartile range).

END, early neurological deterioration; DWI, diffusion-weighted imaging.

Table 3. Receiver operating characteristic curve analysis of imaging variables of each threshold for predicting early neurological deterioration

\begin{tabular}{|c|c|c|c|c|c|c|}
\hline Imaging variable & AUC & $95 \% \mathrm{Cl}$ & Youden's Index & Sensitivity & Specificity & $P$ \\
\hline \multicolumn{7}{|l|}{ Tmax delay } \\
\hline$>2 \mathrm{sec}$ & 0.585 & $0.461-0.709$ & 0.22 & 0.57 & 0.65 & 0.165 \\
\hline$>4 \mathrm{sec}$ & 0.710 & $0.601-0.818$ & 0.36 & 0.49 & 0.88 & 0.001 \\
\hline$>6 \mathrm{sec}$ & 0.725 & $0.622-0.829$ & 0.36 & 0.49 & 0.88 & $<0.001$ \\
\hline$>8 \mathrm{sec}$ & 0.703 & $0.593-0.813$ & 0.35 & 0.60 & 0.75 & 0.001 \\
\hline$>10 \mathrm{sec}$ & 0.665 & $0.548-0.781$ & 0.34 & 0.57 & 0.77 & 0.007 \\
\hline \multicolumn{7}{|l|}{ Mismatch volume } \\
\hline Tmax >4 sec - DWI & 0.718 & $0.611-0.825$ & 0.37 & 0.54 & 0.83 & $<0.001$ \\
\hline Tmax >6 sec - DWI & 0.753 & $0.654-0.852$ & 0.40 & 0.68 & 0.72 & $<0.001$ \\
\hline \multicolumn{7}{|c|}{ Mild hypoperfusion lesion } \\
\hline $\operatorname{Tmax} 2-6 \mathrm{sec}$ & 0.509 & $0.388-0.631$ & 0.15 & 0.51 & 0.63 & 0.880 \\
\hline Tmax 4-6 sec & 0.648 & $0.535-0.762$ & 0.34 & 0.62 & 0.72 & 0.016 \\
\hline
\end{tabular}

$\mathrm{AUC}$, area under the curve; $\mathrm{Cl}$, confidence interval; $\mathrm{DWI}$, diffusion-weighted imaging.

Table 4. Logistic regression analysis investigating the association between clinical and imaging variables and early neurological deterioration

\begin{tabular}{|c|c|c|c|c|c|c|c|c|}
\hline Variable & $\begin{array}{l}\text { Crude OR } \\
(95 \% \mathrm{Cl})\end{array}$ & $P$ & $\begin{array}{c}\text { Adjusted OR } \\
(95 \% \mathrm{Cl}) \text { Model } 1\end{array}$ & $P$ & $\begin{array}{c}\text { Adjusted OR } \\
(95 \% \mathrm{Cl}) \text { Model } 2\end{array}$ & $P$ & $\begin{array}{c}\text { Adjusted OR } \\
(95 \% \mathrm{Cl}) \text { Model } 3\end{array}$ & $P$ \\
\hline $\operatorname{Tmax}>6 \mathrm{sec}^{*}$ & $6.77(2.44-18.77)$ & $<0.001$ & 12.78 (3.36-48.65) & $<0.001$ & NA & NA & NA & NA \\
\hline $\operatorname{Tmax}>6 \mathrm{sec}-\mathrm{DWI}^{+}$ & $5.34(2.17-13.11)$ & $<0.001$ & NA & NA & $5.73(2.04-16.08)$ & 0.001 & NA & NA \\
\hline Tmax 4-6 sec ${ }^{\ddagger}$ & $4.21(1.75-10.15)$ & 0.001 & NA & NA & NA & NA & $9.13(2.76-30.17)$ & $<0.001$ \\
\hline Onset-to-door time (hr) & $0.89(0.81-0.97)$ & 0.008 & NA & NA & NA & NA & NA & NA \\
\hline IV tPA & $7.21(2.68-19.36)$ & $<0.001$ & $7.68(2.52-23.43)$ & $<0.001$ & $5.97(2.05-17.40)$ & 0.001 & $14.94(4.18-53.33)$ & $<0.001$ \\
\hline Initial DWI volume (mL) & $0.95(0.88-1.03)$ & 0.239 & $0.88(0.78-1.001)$ & 0.052 & $0.92(0.82-1.03)$ & 0.131 & NA & NA \\
\hline
\end{tabular}

Model 1 was adjusted for Tmax $>6$ seconds $\geq 53.73 \mathrm{~mL}$, onset-to-door time, IV tPA, and initial DWI volume; Model 2 was adjusted for Tmax $>6$ seconds - DWI $\geq 32.77 \mathrm{~mL}$, onset-to-door time, IV tPA, and initial DWI volume; Model 3 was adjusted for Tmax 4-6 seconds $\geq 55.20 \mathrm{~mL}$, onset-to-door time, IV tPA, and initial DWI volume.

$\mathrm{OR}$, odds ratio; $\mathrm{Cl}$, confidence interval; NA, not applicable; DWI, diffusion-weighted imaging; IV tPA, intravenous tissue-type plasminogen activator.

${ }^{*} T \max >6$ seconds volume over $53.73 \mathrm{~mL}$; 'Tmax >6 seconds - DWI volume over $32.77 \mathrm{~mL}$; ${ }^{~} T \max 4-6$ seconds volume over $55.20 \mathrm{~mL}$.

er variables, including pre-stroke mRS in all three models and baseline glucose in models 2 and 3, were independent predictors of an unfavorable outcome at 3 months.

\section{Discussion}

This study shows that END occurs frequently (39.4\%) in pa- 
Table 5. Logistic regression analysis investigating the association between clinical and imaging variables and 3-month unfavorable outcome

\begin{tabular}{|c|c|c|c|c|c|c|c|c|}
\hline Variable & $\begin{array}{l}\text { Crude OR } \\
(95 \% \mathrm{Cl})\end{array}$ & $P$ & $\begin{array}{c}\text { Adjusted OR } \\
\text { (95\% Cl) Model } 1\end{array}$ & $P$ & $\begin{array}{c}\text { Adjusted OR } \\
(95 \% \mathrm{Cl}) \text { Model } 2\end{array}$ & $P$ & $\begin{array}{c}\text { Adjusted OR } \\
(95 \% \mathrm{Cl}) \text { Model } 3\end{array}$ & $P$ \\
\hline $\operatorname{Tmax}>6 \mathrm{sec}^{*}$ & $11.82(3.55-39.29)$ & $<0.001$ & $23.72(4.79-117.47)$ & $<0.001$ & NA & NA & NA & NA \\
\hline Tmax $>6 \mathrm{sec}-\mathrm{DWI}^{+}$ & $5.69(1.69-19.13)$ & 0.005 & NA & NA & $12.47(2.43-64.09)$ & 0.003 & NA & NA \\
\hline Tmax 4-6 $\mathrm{sec}^{\ddagger}$ & $4.44(1.42-13.95)$ & 0.011 & NA & NA & NA & NA & $5.61(1.56-20.19)$ & 0.008 \\
\hline Baseline glucose (/5 mg/dL) & $1.05(1.00-1.10)$ & 0.051 & NA & NA & $1.06(1.002-1.12)$ & 0.044 & $1.06(1.01-1.12)$ & 0.032 \\
\hline Pre-stroke mRS & $4.71(1.37-16.18)$ & 0.014 & 13.78 (2.31-82.14) & 0.004 & $14.32(2.49-82.44)$ & 0.003 & $6.67(1.66-26.79)$ & 0.007 \\
\hline
\end{tabular}

Model 1 was adjusted for Tmax $>6$ seconds $\geq 53.73 \mathrm{~mL}$, baseline glucose, and pre-stroke $\mathrm{mRS}$; Model 2 was adjusted for Tmax $>6$ seconds $-\mathrm{DWI} \geq 32.77 \mathrm{~mL}$, baseline glucose, and pre-stroke mRS; Model 3 was adjusted for Tmax 4-6 seconds $\geq 55.20 \mathrm{~mL}$, baseline glucose, and pre-stroke mRS. $\mathrm{OR}$, odds ratio; $\mathrm{Cl}$, confidence interval; $\mathrm{NA}$, not applicable; $\mathrm{DWI}$, diffusion-weighted imaging; $\mathrm{mRS}$, modified Rankin Scale.

*Tmax >6 seconds volume over $53.73 \mathrm{~mL}$; ${ }^{*}$ Tmax $>6$ seconds - DWI volume over $32.77 \mathrm{~mL}$; ${ }^{\text {T}}$ Tmax 4-6 seconds volume over $55.20 \mathrm{~mL}$.

tients with minor stroke and LVO. The optimal imaging variables for predicting END were Tmax $>6$ seconds, Tmax $>6 \mathrm{sec}-$ onds - DWI, and Tmax 4-6 seconds, respectively. Specifically, large critical hypoperfusion lesion volume (Tmax $>6$ seconds $\geq 53.73 \mathrm{~mL}$ ), mismatch pattern (Tmax $>6$ seconds $-\mathrm{DWI} \geq 32.77$ $\mathrm{mL}$ ), and large mild hypoperfusion lesion volume (Tmax 4-6 seconds $\geq 55.20 \mathrm{~mL}$ ) were associated with END. These imaging variables were also associated with unfavorable functional outcomes at 3 months.

Previous studies have demonstrated that a mismatch volume or ratio was associated with END. ${ }^{25,26}$ However, these studies enrolled patients regardless of LVO, and one included a patient with relatively severe stroke with an NIHSS score of $\geq 6 .{ }^{25}$ Accordingly, optimal imaging variables predicting END in minor stroke and LVO remain unknown. Although a recent study failed to find radiological predictors of END in a similar patient population, patients with END tended to have larger Tmax $>6$ seconds lesion volumes, ${ }^{34}$ which is in line with our findings. The current and earlier studies suggest that critical hypoperfusion lesions on magnetic resonance imaging would reliably reflect collateral status, ${ }_{1}^{35,36}$ which is an important determinant of fluctuations of neurological status. ${ }^{37-39}$ In addition, our results suggest that mismatch lesions and mild hypoperfusion lesions could be another predictor of END, and these lesions are at risk of progressing to the infarct core in patients with minor stroke and acute LVO. Patients treated with IPA were also independently related to END. However, the results should be interpreted with caution. As treatment strategies were determined at the discretion of the attending physicians, patients expected to have poorer outcomes may have had a higher chance of receiving tPA. Although not statistically significant, patients who received tPA had larger Tmax $>6$ seconds and Tmax $>6$ seconds - DWI volume than those who did not. Furthermore, patients treated with tPA had shorter onset-to-door times and thus received medical attention for a longer time, and thus had a higher chance of neurological worsening being detected by physicians (Supplementary Table 1). ${ }^{32}$

Given the association between END and perfusion status in patients with minor stroke and acute LVO, restoration of perfusion deficits might be considered as a potential treatment strategy for patients at high risk of END. Since delaying EVT until neurologic worsening appears to reduce its beneficial effect, ${ }^{6,20,21}$ immediate EVT might be considered in cases of minor stroke and LVO with a large critical hypoperfusion lesion volume, mismatch pattern, or a large mild hypoperfusion lesion volume. Further well-designed clinical trials should be conducted to prove the benefit of immediate EVT in minor stroke patients with a high risk of END.

Our study has several limitations. Due to its retrospective design, selection bias cannot be ruled out. Patients who were deemed to have neurological worsening were possibly treated with immediate EVT and excluded from this study ( $n=14)$. They had a larger mismatch volume between Tmax $>6$ seconds and DWI (median $51.98 \mathrm{~mL}$ [IQR, 25.61 to 129.21]) and Tmax >6 seconds lesion volume (62.33 mL [IOR, 10.15 to 56.67]) (Supplementary Tables 2 and 3). Despite this bias, END was frequent (39.4\%) in our study cohort. Another shortcoming may be unmeasured confounders. Further, as the perfusion status of each tissue may dynamically change over time in the acute stage of stroke, ${ }^{40}$ a single PWI snapshot may not accurately reflect temporal change and may be an inaccurate predictor. In addition, follow-up neuroimaging was not available in most patients, and therefore we were not able to consider the effect of spontaneous recanalization on clinical outcomes.

\section{Conclusions}

In conclusion, our study showed that END was frequent in patients with minor stroke and acute LVO and could be predicted using perfusion/diffusion imaging variables. Tmax $>6$ seconds 
$\geq 53.73 \mathrm{~mL}$, Tmax $>6$ seconds $-\mathrm{DWI} \geq 32.77 \mathrm{~mL}$, and Tmax 4-6 seconds $\geq 55.20 \mathrm{~mL}$ were independently associated with END and unfavorable functional outcomes at 3 months. These thresholds could be considered as reference values to select candidates for immediate EVT in minor stroke patients at a high risk of END to improve outcomes.

\section{Supplementary materials}

Supplementary materials related to this article can be found online at https://doi.org/10.5853/jos.2020.01466.

\section{Disclosure}

The authors have no financial conflicts of interest.

\section{References}

1. Heldner MR, Zubler C, Mattle HP, Schroth G, Weck A, Mono $M L$, et al. National Institutes of Health stroke scale score and vessel occlusion in 2152 patients with acute ischemic stroke. Stroke 2013;44:1153-1157.

2. Reeves M, Khoury J, Alwell K, Moomaw C, Flaherty M, Woo D, et al. Distribution of national institutes of health stroke scale in the Cincinnati/Northern Kentucky stroke study. Stroke 2013;44:3211-3213.

3. Spokoyny I, Raman R, Ernstrom K, Khatri P, Meyer DM, Hemmen $T M$, et al. Defining mild stroke: outcomes analysis of treated and untreated mild stroke patients. J Stroke Cerebrovasc Dis 2015;24:1276-1281.

4. Khatri P, Conaway MR, Johnston KC; Acute Stroke Accurate Prediction Study (ASAP) Investigators. Ninety-day outcome rates of a prospective cohort of consecutive patients with mild ischemic stroke. Stroke 2012;43:560-562.

5. Romano JG, Smith EE, Liang L, Gardener H, Camp S, Shuey L, et al. Outcomes in mild acute ischemic stroke treated with intravenous thrombolysis: a retrospective analysis of the Get With the Guidelines-Stroke registry. JAMA Neurol 2015;72: 423-431.

6. Messer MP, Schönenberger S, Möhlenbruch MA, Pfaff J, Herweh $C_{1}$ Ringleb PA, et al. Minor stroke syndromes in largevessel occlusions: mechanical thrombectomy or thrombolysis only? AJNR Am J Neuroradiol 2017;38:1177-1179.

7. Rajajee V, Kidwell C, Starkman S, Ovbiagele B, Alger JR, Villablanca $\mathrm{P}$, et al. Early MRI and outcomes of untreated patients with mild or improving ischemic stroke. Neurology 2006; 67:980-984.

8. Kim JT, Park MS, Chang J, Lee JS, Choi KH, Cho KH. Proximal arterial occlusion in acute ischemic stroke with low NIHSS scores should not be considered as mild stroke. PLoS One 2013;8:e70996.

9. Saver JL, Goyal M, Bonafe A, Diener HC, Levy El, Pereira VM, et al. Stent-retriever thrombectomy after intravenous t-PA vs. t-PA alone in stroke. N Engl J Med 2015;372:2285-2295.

10. Campbell BC, Mitchell PJ, Kleinig TJ, Dewey HM, Churilov L, Yassi $N$, et al. Endovascular therapy for ischemic stroke with perfusion-imaging selection. N Engl J Med 2015;372:10091018.

11. Goyal M, Demchuk AM, Menon BK, Eesa M, Rempel JL, Thornton J, et al. Randomized assessment of rapid endovascular treatment of ischemic stroke. N Engl J Med 2015;372: 1019-1030.

12. Jovin TG, Chamorro $A$, Cobo $E$, de Miquel MA, Molina CA, Rovira $A$, et al. Thrombectomy within 8 hours after symptom onset in ischemic stroke. N Engl J Med 2015;372:2296-2306.

13. Bracard S, Ducrocq $X$, Mas $J L$, Soudant M, Oppenheim C, Moulin $T$, et al. Mechanical thrombectomy after intravenous alteplase versus alteplase alone after stroke (THRACE): a randomised controlled trial. Lancet Neurol 2016;15:1138-1147.

14. Albers GW, Marks MP, Kemp S, Christensen S, Tsai JP, OrtegaGutierrez S, et al. Thrombectomy for stroke at 6 to 16 hours with selection by perfusion imaging. N Engl J Med 2018;378: 708-718.

15. Nogueira RG, Jadhav AP, Haussen DC, Bonafe A, Budzik RF, Bhuva $P$, et al. Thrombectomy 6 to 24 hours after stroke with a mismatch between deficit and infarct. N Engl J Med 2018; 378:11-21.

16. Wolman DN, Marcellus DG, Lansberg MG, Albers G, Guenego $A$, Marks MP, et al. Endovascular versus medical therapy for large-vessel anterior occlusive stroke presenting with mild symptoms. Int J Stroke 2020;15:324-331.

17. Dargazanli C, Arquizan C, Gory B, Consoli A, Labreuche J, Redjem $\mathrm{H}$, et al. Mechanical thrombectomy for minor and mild stroke patients harboring large vessel occlusion in the anterior circulation: a multicenter cohort study. Stroke 2017; 48:3274-3281.

18. Sarraj A, Hassan A, Savitz SI, Grotta JC, Cai C, Parsha KN, et al. Endovascular thrombectomy for mild strokes: how low should we go? Stroke 2018;49:2398-2405.

19. Urra X, San Román L, Gil F, Millán M, Cánovas D, Roquer J, et al. Medical and endovascular treatment of patients with large vessel occlusion presenting with mild symptoms: an observational multicenter study. Cerebrovasc Dis 2014;38: 418-424.

20. Nagel $S$, Bouslama M, Krause LU, Küpper $C$, Messer M, Petersen $M$, et al. Mechanical thrombectomy in patients with 
milder strokes and large vessel occlusions. Stroke 2018;49: 2391-2397.

21. Haussen DC, Bouslama M, Grossberg JA, Anderson A, Belagage $S$, Frankel $M$, et al. Too good to intervene? Thrombectomy for large vessel occlusion strokes with minimal symptoms: an intention-to-treat analysis. J Neurointerv Surg 2017;9:917-921.

22. Haussen DC, Lima FO, Bouslama M, Grossberg JA, Silva GS, Lev $\mathrm{MH}$, et al. Thrombectomy versus medical management for large vessel occlusion strokes with minimal symptoms: an analysis from STOPStroke and GESTOR cohorts. J Neurointerv Surg 2018;10:325-329.

23. Siegler JE, Boehme AK, Albright KC, George AJ, Monlezun DJ, Beasley TM, et al. A proposal for the classification of etiologies of neurologic deterioration after acute ischemic stroke. $J$ Stroke Cerebrovasc Dis 2013;22:e549-e556.

24. Gawlitza M, Gragert J, Quäschling U, Hoffmann KT. FLAIRhyperintense vessel sign, diffusion-perfusion mismatch and infarct growth in acute ischemic stroke without vascular recanalisation therapy. J Neuroradiol 2014;41:227-233.

25. Hsu CY, Cheng CY, Tsai YH, Lee JD, Yang JT, Weng HH, et al. Perfusion-diffusion mismatch predicts early neurological deterioration in anterior circulation infarction without thrombolysis. Curr Neurovasc Res 2015;12:277-282.

26. Asdaghi N, Hill MD, Coulter Jl, Butcher KS, Modi J, Qazi A, et al. Perfusion MR predicts outcome in high-risk transient ischemic attack/minor stroke: a derivation-validation study. Stroke 2013;44:2486-2492.

27. Ko Y, Lee S, Chung JW, Han MK, Park JM, Kang K, et al. MRIbased algorithm for acute ischemic stroke subtype classification. J Stroke 2014;16:161-172.

28. Olivot JM, Mlynash M, Thijs VN, Kemp S, Lansberg MG, Wechsler $L$, et al. Optimal Tmax threshold for predicting penumbral tissue in acute stroke. Stroke 2009;40:469-475.

29. Takasawa M, Jones PS, Guadagno JV, Christensen S, Fryer TD, Harding $S$, et al. How reliable is perfusion MR in acute stroke? Validation and determination of the penumbra threshold against quantitative PET. Stroke 2008;39:870-877.

30. Saji N, Kimura K, Kawarai T, Shimizu H, Kita Y. Arterial stiff- ness and progressive neurological deficit in patients with acute deep subcortical infarction. Stroke 2012;43:30883090.

31. Jeong $H G$, Kim BJ, Yang MH, Han MK, Bae HJ. Neuroimaging markers for early neurologic deterioration in single small subcortical infarction. Stroke 2015;46:687-691.

32. Hwang YH, Seo JG, Lee HW, Park SP, Suh CK. Early neurological deterioration following intravenous recombinant tissue plasminogen activator therapy in patients with acute lacunar stroke. Cerebrovasc Dis 2008;26:355-359.

33. Youden WJ. Index for rating diagnostic tests. Cancer 1950;3:3235.

34. Saleem Y, Nogueira RG, Rodrigues GM, Kim S, Sharashidze V, Frankel $M$, et al. Acute neurological deterioration in large vessel occlusions and mild symptoms managed medically. Stroke 2020;51:1428-1434.

35. Bang OY, Goyal M, Liebeskind DS. Collateral circulation in ischemic stroke: assessment tools and therapeutic strategies. Stroke 2015;46:3302-3309.

36. Bang OY, Saver JL, Buck BH, Alger JR, Starkman S, Ovbiagele $B$, et al. Impact of collateral flow on tissue fate in acute ischaemic stroke. J Neurol Neurosurg Psychiatry 2008;79: 625-629.

37. Fanou EM, Knight J, Aviv RI, Hojjat SP, Symons SP, Zhang L, et al. Effect of collaterals on clinical presentation, baseline imaging, complications, and outcome in acute stroke. AJNR Am J Neuroradiol 2015;36:2285-2291.

38. Miteff F, Levi CR, Bateman GA, Spratt N, McElduff P, Parsons MW. The independent predictive utility of computed tomography angiographic collateral status in acute ischaemic stroke. Brain 2009;132:2231-2238.

39. Shuaib A, Butcher $K$, Mohammad AA, Saqqur M, Liebeskind DS. Collateral blood vessels in acute ischaemic stroke: a potential therapeutic target. Lancet Neurol 2011;10:909-921.

40. Campbell BC, Christensen S, Tress BM, Churilov L, Desmond $\mathrm{PM}$, Parsons MW, et al. Failure of collateral blood flow is associated with infarct growth in ischemic stroke. J Cereb Blood Flow Metab 2013;33:1168-1172. 
Supplementary Table 1. Patients' characteristics by IV tPA status

\begin{tabular}{|c|c|c|c|}
\hline Characteristic & IV tPA $(n=28)$ & No IV tPA $(n=66)$ & $P$ \\
\hline Baseline NIHSS & $2.04 \pm 1.71$ & $2.15 \pm 1.61$ & 0.755 \\
\hline Onset-to-door time (hr) & $1.33(0.89-2.20)$ & $5.36(2.38-13.38)$ & $<0.001$ \\
\hline Site of occlusion & & & 0.134 \\
\hline Intracranial ICA & $0(0)$ & $7(10.6)$ & \\
\hline Tandem & $1(3.6)$ & $5(7.6)$ & \\
\hline MCA M1 & $12(42.9)$ & $32(48.5)$ & \\
\hline MCA M2 trunk & $15(53.6)$ & $22(33.3)$ & \\
\hline Baseline glucose (mg/dL) & $144.2 \pm 53.5$ & $143.6 \pm 50.9$ & 0.963 \\
\hline Initial DWI volume (mL) & $0.52(0.00-5.97)$ & $1.53(0.17-5.52)$ & 0.380 \\
\hline $\operatorname{Tmax}>6 \sec (\mathrm{mL})$ & $40.62(15.86-57.96)$ & $25.47(5.23-52.30)$ & 0.383 \\
\hline Tmax >6 sec - DWI (mL) & $37.42(12.36-54.64)$ & $21.79(3.18-41.37)$ & 0.298 \\
\hline Tmax 4-6 sec (mL) & 35.09 (26.34-83.93) & 51.16 (28.42-81.39) & 0.185 \\
\hline
\end{tabular}

Values are presented as mean \pm standard deviation, median (interquartile range), or number (\%).

IV tPA, intravenous tissue-type plasminogen activator; NIHSS, National Institutes of Health Stroke Scale; ICA, internal carotid artery; MCA, middle cerebral artery; DWI, diffusion-weighted imaging. 
Supplementary Table 2. Baseline demographics of enrolled patients and patients who underwent EVT before END

\begin{tabular}{|c|c|c|c|}
\hline Variable & Enrolled patients $(n=94)$ & Excluded patients: EVT before END $(n=14)$ & $P$ \\
\hline Age $(y r)$ & $66.9 \pm 13.0$ & $67.5 \pm 15.0$ & 0.887 \\
\hline Men & $49(52.1)$ & $10(71.4)$ & 0.176 \\
\hline Baseline NIHSS & $2.12 \pm 1.63$ & $3.93 \pm 1.49$ & $<0.001$ \\
\hline Onset-to-door time (hr) & $3.23(1.45-9.33)$ & $2.93(0.65-5.00)$ & 0.141 \\
\hline Pre-stroke mRS & & & 1.000 \\
\hline 0 & $80(85.1)$ & $12(85.7)$ & \\
\hline 1 & $14(14.9)$ & $2(14.3)$ & \\
\hline Stroke mechanism & & & 0.705 \\
\hline LAA & $42(44.7)$ & $5(35.7)$ & \\
\hline CE & $36(38.3)$ & $7(50.0)$ & \\
\hline Other determined & $0(0)$ & $0(0)$ & \\
\hline Undetermined & $16(17.0)$ & $2(14.3)$ & \\
\hline Site of occlusion & & & 0.020 \\
\hline Intracranial ICA & $7(7.4)$ & $0(0.0)$ & \\
\hline Tandem & $6(6.4)$ & $3(21.4)$ & \\
\hline MCA M1 & $44(46.8)$ & $10(71.4)$ & \\
\hline MCA M2 trunk & $37(39.4)$ & $1(7.1)$ & \\
\hline Hypertension & $63(67.0)$ & $9(64.3)$ & 1.000 \\
\hline Diabetes mellitus & $25(26.6)$ & $3(21.4)$ & 1.000 \\
\hline Hyperlipidemia & 37 (39.4) & $4(28.6)$ & 0.438 \\
\hline Atrial fibrillation & $26(27.7)$ & $5(35.7)$ & 0.538 \\
\hline MI or angina & $9(9.6)$ & $1(7.1)$ & 1.000 \\
\hline Prior stroke & $11(11.7)$ & $2(14.3)$ & 0.675 \\
\hline Smoking & $19(20.2)$ & $4(28.6)$ & 0.491 \\
\hline $\mathrm{SBP}(\mathrm{mm} \mathrm{Hg})$ & $157.2 \pm 31.1$ & $160.0 \pm 35.4$ & 0.869 \\
\hline $\mathrm{DBP}(\mathrm{mm} \mathrm{Hg})$ & $86.57 \pm 17.0$ & $88.9 \pm 12.4$ & 0.699 \\
\hline 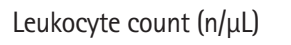 & $8,075.1 \pm 2,324.8$ & $8,581.4 \pm 3,376.1$ & 0.883 \\
\hline Hemoglobin (g/dL) & $13.7 \pm 1.5$ & $12.9 \pm 3.5$ & 0.998 \\
\hline Hematocrit (\%) & $39.9 \pm 4.1$ & $39.5 \pm 4.1$ & 0.855 \\
\hline Platelet count $(n / \mu \mathrm{L})$ & $245,053 \pm 74,857$ & $209,143 \pm 58,010$ & 0.075 \\
\hline $\mathrm{ESR}(\mathrm{mm} / \mathrm{hr})$ & $10.0(5.0-19.0)$ & $5.0(2.0-12.5)$ & 0.036 \\
\hline $\mathrm{CRP}(\mathrm{mg} / \mathrm{dL})$ & $0.25(0.08-0.34)$ & $0.16(0.09-0.30)$ & 0.922 \\
\hline Fibrinogen (mg/dL) & $287.2 \pm 82.7$ & $268.3 \pm 66.8$ & 0.539 \\
\hline Baseline glucose (mg/dL) & $143.8 \pm 51.4$ & $149.0 \pm 75.0$ & 0.991 \\
\hline \multicolumn{4}{|c|}{ Type of recanalization therapy } \\
\hline IV tPA & $28(29.8)$ & $4(28.6)$ & 1.000 \\
\hline Rescue EVT & $23(24.5)$ & $14(100.0)$ & $<0.001$ \\
\hline
\end{tabular}

Values are presented as mean \pm standard deviation, number (\%), or median (interquartile range).

EVT, endovascular therapy; END, early neurological deterioration; NIHSS, National Institutes of Health Stroke Scale; mRS, modified Rankin Scale; LAA, large artery atherosclerosis; $\mathrm{CE}$, cardioembolism; ICA, internal carotid artery; MCA, middle cerebral artery; MI, myocardial infarction; SBP, systolic blood pressure; $\mathrm{DBP}$, diastolic blood pressure; ESR, erythrocyte sedimentation rate; CRP, C-reactive protein; IV tPA, intravenous tissue-type plasminogen activator. 
Supplementary Table 3. Imaging variables of enrolled patients and patients who underwent EVT before END

\begin{tabular}{|c|c|c|c|}
\hline Variable & Enrolled patients $(n=94)$ & Excluded patients: EVT before END* & $P$ \\
\hline Initial DWI volume $(\mathrm{mL})$ & $1.34(0.00-5.61)$ & $3.45(1.46-7.80)$ & 0.065 \\
\hline $\operatorname{Tmax}>2 \sec (\mathrm{mL})$ & $217.62(156.56-274.25)$ & $273.00(215.14-357.00)$ & 0.044 \\
\hline $\operatorname{Tmax}>4 \sec (\mathrm{mL})$ & $84.24(47.78-120.57)$ & 128.65 (77.16-208.59) & 0.013 \\
\hline $\operatorname{Tmax}>6 \sec (\mathrm{mL})$ & $28.97(10.15-56.67)$ & $62.33(28.81-131.16)$ & 0.018 \\
\hline $\operatorname{Tmax}>8 \sec (\mathrm{mL})$ & $12.53(0.00-25.10)$ & $32.46(3.47-77.81)$ & 0.080 \\
\hline $\operatorname{Tmax}>10 \sec (\mathrm{mL})$ & $3.85(0.00-12.70)$ & $16.41(0.00-45.91)$ & 0.082 \\
\hline Tmax >4 sec - DWI (mL) & $75.21(43.27-118.17)$ & $128.65(72.89-206.64)$ & 0.017 \\
\hline Tmax >6 sec - DWI (mL) & $24.96(6.45-46.25)$ & $51.98(25.61-129.21)$ & 0.024 \\
\hline Tmax 2-6 sec (mL) & 185.54 (131.62-229.11) & 198.23 (154.99-233.46) & 0.709 \\
\hline Tmax 4-6 sec (mL) & 47.19 (28.10-76.63) & $60.11(45.70-76.88)$ & 0.353 \\
\hline
\end{tabular}

Values are presented as median (interquartile range).

EVT, endovascular therapy; END, early neurological deterioration; DWI, diffusion-weighted imaging.

*Of the 14 excluded patients who received EVT before END, those who had missing data on DWI $(n=1)$ and perfusion variables $(n=5)$ were excluded from the corresponding analysis. 
158 From January 2011 to May 2019

(1) Acute ischemic stroke patients

(2) Onset to arrival within 24 hours

(3) Baseline NIHSS score of 5 or less

(4) Pre-stroke $m R S$ of 0 or 1

(5) LVO in the anterior circulation (IC-ICA, MCA M1, M2 trunk, or tandem occlusion)

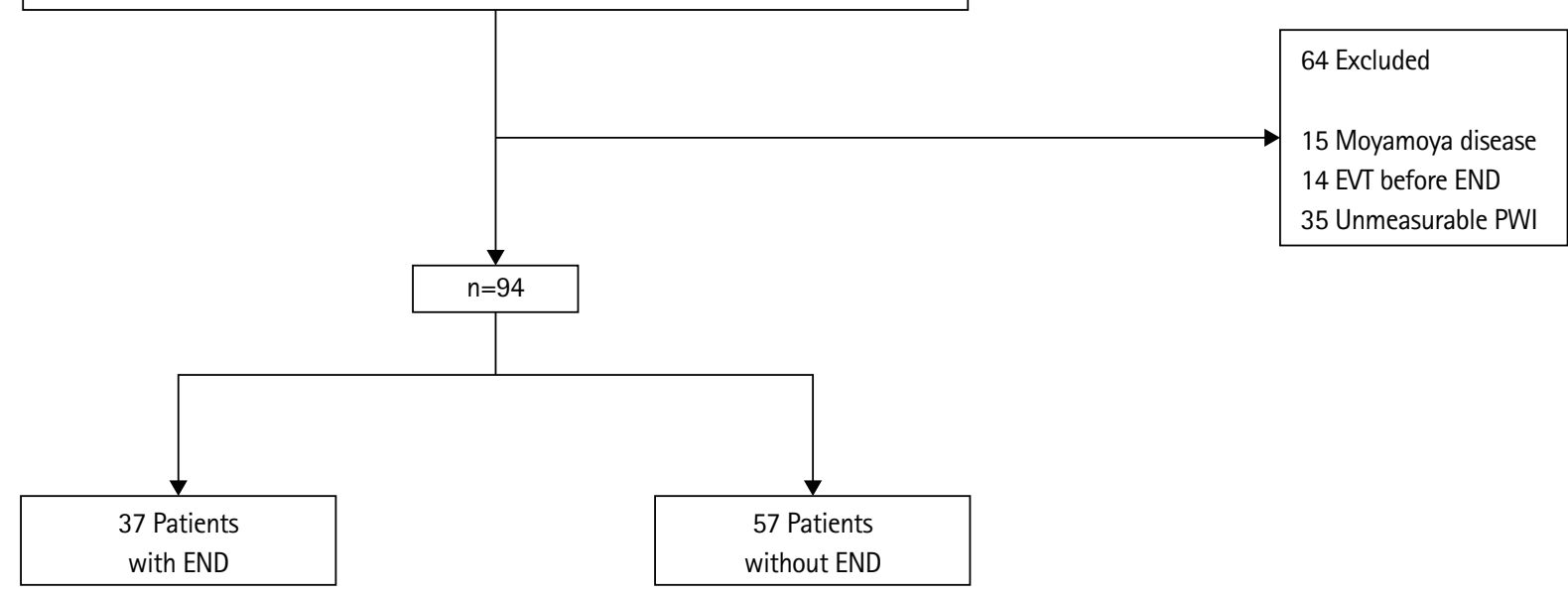

Supplementary Figure 1. Flowchart of patient screening and enrollment. NIHSS, National Institutes of Health Stroke Scale; mRS, modified Rankin Scale; LVO, large vessel occlusion; IC-ICA, intracranial internal carotid artery; MCA, middle cerebral artery; EVT, endovascular treatment; END, early neurological deterioration; PWI, perfusion-weighted imaging. 